\title{
Questionnaire survey on nutritional supplement therapy and exercise training at hemodialysis facilities in Japan
}

\author{
Satoko Sakurai ${ }^{1}$, Norio Hanafusa ${ }^{2 *}$, Hideki Kato ${ }^{1}$, Shinji lizaka ${ }^{3}$, Ryoko Murayama ${ }^{4}$ and Masaomi Nangaku ${ }^{1}$
}

\begin{abstract}
Background: Nutritional therapy and exercise training (ET) are important interventions for hemodialysis patients. We investigated the status of nutritional therapy and ET provided at hemodialysis facilities across Japan.

Method: This was a cross-sectional study. The facilities investigated were 3993 facility member institutions of the Japanese Society for Dialysis Therapy in August 2015. Data was collected on the facility type, number of staff (doctors, nurses, and medic al engineers), presence of staff (clinical dietitians, pharmacists, and physical therapists), proportion of elderly patients (age $\geq 65$ years), patients with albumin $\leq 3.5 \mathrm{~g} / \mathrm{dL}$, and types of oral nutritional supplements (ONS), intradialytic parenteral nutrition (IDPN), and ET in the facility. We summarized data on facilities and patient characteristics and calculated the proportion of the nutrition that were ONS, IDPN, and exercise interventions provided. We used multiple logistic analyses to examine the facility characteristics associated with the provision of nutritional support and ET.

Results: We obtained responses from 1048 facilities (response rate 26.2\%) and 88,492 patients (27.6\%). Patients aged $\geq$ 65 years accounted for $63.4 \%$ of all investigated patients. Patients with Alb $\leq 3.5 \mathrm{~g} / \mathrm{dL}$ accounted for $37.6 \%$ of all investigated patients. Meals during hemodialysis sessions were provided at 601 facilities (64\%), ONS were used at 382 facilities (40\%), and IDPN was administered at 471 facilities (46\%). Exercise during hemodialysis sessions was provided at 190 facilities (20\%). These trends did not change after adjustment of response rates by affiliations of facility type and region. At the patient level, only a limited number of patients were provided with ONS, IDPN, and ET, 2.1, 2.7, and 3.0\%, respectively. ONS and IDPN were less likely to be offered in hospitals than in clinics without beds (odds ratio (OR) 0.21 ; $95 \%$ confidence interval (Cl) 0.09-0.45) (OR 0.37; 95\% Cl 0.17-0.82). ET was also less likely to be offered in hospitals (OR 0.20; 95\% Cl 0.08-0.49).
\end{abstract}

Conclusions: Nutritional support therapy is provided in a considerable number of hemodialysis facilities, ET is increasing but offered by fewer facilities compared to other countries, while a limited number of patients were provided with ET.

Keywords: Hemodialysis, Questionnaire, Nutritional therapy, Exercise training, National survey

\section{Background}

The aging population features prominently among hemodialysis patients and is influencing the epidemiological characteristics of this patient group. The average age of incident patients and prevalent patients is more than 65 years, and the increase in the dialysis population is currently due to an increase in patients aged 70 years or

\footnotetext{
*Correspondence: hanafusa@twmu.ac.jp

${ }^{2}$ Department of Blood Purification, Kidney Center Tokyo Women's Medical

University, 8-1 Kawada-cho, Shinjuku-ku, Tokyo 162-8666, Japan

Full list of author information is available at the end of the article
}

more [1]. Protein energy wasting (PEW), frailty, and sarcopenia are often found in patients with advanced chronic kidney disease and end-stage kidney disease $[2,3]$. These conditions are reportedly associated with each other. Moreover, they are related to higher mortality and morbidity [4-6], especially among elderly individuals in whom physical functions and nutritional status have deteriorated. Older patients are more vulnerable than younger populations to further decline in these parameters [2, 7-9].

In the dialysis population, the two primary options to maintain and even improve nutritional condition and 
physical function are nutritional therapy and exercise training (ET), provided either within or outside the dialysis facilities. For nutritional therapy, oral nutritional supplements (ONS) given during hemodialysis can be associated with better survival of dialysis patients [10-13]. In fact, some dialysis facilities offer meals during the sessions [14]. In the USA, dialysis facilities used to restrict eating during hemodialysis, but in recent years, they have been shifting toward allowing patients to eat meals [15]. Many studies and meta-analyses have shown that ET improves physical function, muscular strength, and functional capacity [16-18], although the details of how, when, and to whom ET should be given during hemodialysis sessions remain unclear.

The needs for nutritional therapy and ET in dialysis facilities are expected to continue to increase, as are the numbers of patients requiring such treatment. However, it is not clear how many facilities are offering nutritional therapy and ET, how many patients are receiving them, or what the detailed characteristics of these facilities are. Such information is fundamental and indispensable for the development of strategic plans for managing older dialysis patients.

This study sought to clarify the current status of nutritional therapy and ET interventions provided at hemodialysis facilities in Japan, in order to identify appropriate intervention points and approaches for initiatives at facilities in the future.

\section{Methods}

\section{Study design}

This was a cross-sectional study conducted using a nationwide questionnaire.

\section{Study population}

The study was conducted in member institutions of the Japanese Society for Dialysis Therapy (JSDT). In total, 3993 facilities were registered as member institutions of JSDT as of August 2015. The survey collected data on the facilities and patients receiving maintenance hemodialysis in these facilities during August 2015.

\section{Study protocol}

The questionnaire consisted of two parts. The first part contained questions regarding the facility itself, and the second part focused on the nutritional support and ET available at the facility (Additional file 1: Item S1). Questionnaires were sent to each facility by postal mail. We asked that completed questionnaires be returned by fax by the end of October 2015 . We also requested that the conditions of dialysis treatments should not be changed while answering this questionnaire.

\section{Data collection}

The collected data included the following:

\section{Facility details}

Type: facility types were classified by their affiliation and size. The classification used by the JSDT annual survey for affiliations of facilities, i.e., national university hospital, private university hospital, national hospital, county municipalities hospital, hospital affiliated to the Japan Community Healthcare Organization, hospital affiliated to Japan Agricultural Cooperatives, other public hospital, private general hospital, private hospital, and private clinic. On the other hand, the original classification of four types according to their sizes were also investigated, i.e. clinic, clinic with beds, hospital ( $<200$ beds), and hospital ( $\geq 200$ beds). The survey of medical facilities by Ministry of Health Labor and Welfare Japan determines the size of hospitals by the numbers of beds in the facility. The hospitals with 200 or more beds are considered large ones [19].

Region: prefecture and municipality in Japan.

Number of staff: number each of doctors, nurses, and clinical engineers.

Presence/absence of pharmacist, clinical dietitian, and physical therapist providing care for patients on dialysis.

Background of treated patients as a whole: number of patients aged $\geq 65$ years, number of patients with albumin $\leq 3.5 \mathrm{~g} / \mathrm{dL}$. We used these cut-off values for the reasons as follows. Regarding the age, the elderly persons were defined as having a chronological age of 65 years in many countries including Japan at the time of this survey [20], about albumin level, the European Society for Clinical Nutrition and Metabolism (ESPEN) guideline described serum albumin $<3.5 \mathrm{~g} / \mathrm{dL}$ as the criteria for severe undernutrition for which nutritional therapy is indicated [21].

2. Intervention provided at hemodialysis facilities: meals, ONS, intradialytic parenteral nutrition (IDPN), and ET

\section{Statistical analyses}

Results are summarized as means and standard deviations for data showing a normal distribution, and as medians and interquartile ranges (IQR) for data not showing a normal distribution. Detailed data are shown as numbers and percentages.

The following were excluded from analyses as outliers: facilities where the percentage of aged ( $\geq 65$ years) or albumin $\leq 3.5 \mathrm{~g} / \mathrm{dL}$ patients exceeded $100 \%$.

Because the response rates, that is the proportion of facility that answered the question, differed by facility type and region, proportions of provision adjusted by affiliations of facility type and region were calculated as an average of the stratum-specific proportions weighted 
by their own proportion in the population. We used the JSDT classification for facility type adjustment and six districts (Hokkaido and Tohoku, Kanto, Chubu and Tokai, Kansai, Chugoku and Shikoku, and Kyusyu and Okinawa) for region adjustment. Differences between unadjusted and adjusted proportions of interventions provided were compared by a chi-square test.

Multiple logistic analyses were used to explore the factors associated with nutritional support and ET offered by the facility. Dependent variables included the provision of meals, ONS, IDPN, and ET at each facility. The facilityrelated factors investigated were as follows: facility type (original four types); region (six regions); number of staff (numbers of doctors, nurses, and clinical engineers) presented as quartiles; presence of staff (clinical dietitians, pharmacists, and physical therapists); proportion of elderly patients (age $\geq 65$ years); and proportion of patients with albumin $\leq 3.5 \mathrm{~g} / \mathrm{dL}$. Reference data were set as follows: size of facility type; clinic without beds, region; Kanto, number of staff; the first quartile values, and presence/absence of staff; absence. We also performed a sensitivity analysis in which per-100-patient staffing level was used instead of actual number of staff as the covariate. In addition, we performed inverse probability of censoring weighted analysis of affiliations of facility type and region specifically for those facilities that provided responses to all items, excluding facilities with logically erroneous data for sensitivity analyses to remove the effect of response rate.

First, we performed multivariate analysis with region and affiliations of facility type as independent variables and actual response rates of these 60 facility groups. Accordingly, regression of facility group against response rate was determined to calculate the response probability of each facility group. Subsequently, a response probability for each facility was assigned based on region and affiliations of facility type. Then, we performed multivariate analysis to investigate factors affecting each therapy, with the reciprocal of the response probability included as the weight for each facility. The proportion of interventions provided was compared between hemodialysis facility groups with response probabilities dichotomized by the median, using the chi-square test to investigate the effects of the provision of interventions on the response probabilities.

We considered $p<0.05$ statistically significant. All analyses were carried out using JMP Pro 11.0 (SAS Institute, NC, USA).

\section{Ethical issues}

The facility name was not specified in the questionnaire. No data that could identify individual patients were collected. Return of the completed questionnaire was deemed as facility consent to participate. This study was conducted in compliance with the Declaration of Helsinki.

\section{Results}

In total, 1048 facilities responded to the questionnaire (response rate 26.2\%). Regarding facility characteristics, $41.3 \%$ of facilities were classed as a "clinic without bed" and $31.9 \%$ of facilities were located in the Kanto region (Table 1). The median number of total staff was 18 per facility (Table 2). In almost half of the facilities, pharmacists and physical therapists were working, irrespective of affiliation to the dialysis center, while clinical dietitians were working in 713 facilities (69.6\%) (Table 3).

For patient characteristics, data were available regarding 88,492 patients (response rate $27.6 \%$ ), of which only $9.6 \%$ were hospitalized; the remaining $90.4 \%$ were outpatients. Elderly patients were predominant, with $63.4 \%$ of the patients aged $\geq 65$ years. The patients with serum albumin $\leq 3.5 \mathrm{~g} / \mathrm{dL}$ accounted for $37.6 \%$ of all investigated patients. The median number of patients per facility was 70 (IQR 42-110) (Table 4).

\section{Nutritional and exercise interventions provided}

Meals during hemodialysis sessions were provided at 601 facilities (63.9\%), ONS were used at 382 facilities (39.8\%), and IDPN was performed at 471 facilities (45.8\%). ET during hemodialysis sessions was provided at 190 facilities (20.2\%). These trends did not change after adjustment by facility type and region. In contrast, the actual patient numbers were lower; that is, the proportions of patients who were offered ONS, IDPN, and ET were 2.1, 2.7, and $3.0 \%$, respectively, of the total patients (Table 5) The proportions of the interventions provided in the facility were not associated with the probabilities of response rates for this survey (Additional file 2: Table S2). This fact indicated that the interest in providing these interventions or the interest in responding to this survey might not affect the actual provision of these therapies.

Table 1 Characteristics of facilities

\begin{tabular}{lll}
\hline & & Number of facilities (\%) \\
\hline Total facilities & & 1048 \\
Facility type & Clinic & $430(41.3)$ \\
& Clinic with beds & $120(11.5)$ \\
& Hospital (<200 beds) & $212(20.4)$ \\
& Hospital ( $\geq 200$ beds) & $279(26.8)$ \\
& Unanswered & 7 \\
Region & Hokkaido, Tohoku & $132(12.8)$ \\
& Kanto & $328(31.9)$ \\
& Chubu, Tokai & $163(15.9)$ \\
& Kansai & $169(16.5)$ \\
& Chugoku, Shikoku & $101(9.8)$ \\
& Kyushu, Okinawa & $135(13.1)$ \\
& Unanswered & 20 \\
\hline
\end{tabular}


Table 2 Number of each type of medical staff per facility and per number of patients and per facility

\begin{tabular}{llll}
\hline & & $\begin{array}{l}\text { Number of staff } \\
\text { per facility, median } \\
\text { (IQR) }\end{array}$ & $\begin{array}{l}\text { Number of staff per } \\
\text { number of } 10 \text { patients } \\
\text { and facility, median (IQR) }\end{array}$ \\
\hline Total staff & $18(12-26)$ & $2.5(1.9-3.5)$ \\
Disciplines & Doctor (full-time) & $1(1-3)$ & $0.2(0.1-0.5)$ \\
& $\begin{array}{l}\text { Doctor (part- } \\
\text { time) }\end{array}$ & $1(0-4)$ & $0.2(0-0.5)$ \\
& Nurse (full-time) & $7(4-11)$ & $1.1(0.8-1.6)$ \\
& Nurse (part-time) & $1(0-2)$ & $0.1(0-0.3)$ \\
& $\begin{array}{l}\text { Clinical engineer } \\
\text { (full-time) }\end{array}$ & $4(1-6)$ & $0.5(0.3-0.8)$ \\
& $\begin{array}{l}\text { Clinical engineer } \\
\text { (part-time) }\end{array}$ & $0(0-0)$ & $0(0-0)$ \\
\hline
\end{tabular}

Polymeric formula was the type of ONS most frequently used (56.1\%) followed by amino acid formula (31.1\%) and formula for kidney failure patients (19.8\%) (Fig. 1). Figure 2 indicates the proportions of patients receiving various components of IDPN. More than half of the patients (59.2\%) received amino acids only. Most of the patients receiving IDPN (91.3\%) were given amino acids in some form; the proportion for glucose or lipids in some form was smaller (29.6 and 17.5\%, respectively) (Fig. 2).

The types of ET offered by the facilities were diverse, including resistance training (RT) and aerobic training (AT), with each intervention type accounting for almost one-third of ET. Most patients (81.8\%) performed ET three times per week (Fig. 3).

Regarding exercise duration, almost half (50.2\%) of the patients performed ET for 15-29 min (Fig. 4). More than half of the facilities that did not offer ET at the time of the study (61.1\%) were considering implementation of ET in the future.

\section{Characteristic factors in facilities associated with each therapy}

ONS were less likely to be offered in hospitals than in clinics without beds $(p<0.01)$. To our surprise, the presence of a clinical dietitian was not associated with the use of ONS $(p=0.59)$. For IDPN, a similar relationship was observed; the therapy was less likely to be used in large hospitals than in clinics $(p=0.01)$. The presence of

Table 3 Facilities with and without relevant staff

\begin{tabular}{llll}
\hline & \multicolumn{2}{l}{ Number of facilities (\%) } \\
\cline { 2 - 4 } & Pharmacist & $\begin{array}{l}\text { Clinical } \\
\text { dietitian }\end{array}$ & $\begin{array}{l}\text { Physical } \\
\text { therapist }\end{array}$ \\
\hline With staff working in HD & $276(26.9)$ & $495(48.3)$ & $200(19.6)$ \\
With staff not working in HD & $272(26.5)$ & $218(21.3)$ & $314(30.8)$ \\
Without staff & $478(46.6)$ & $312(30.4)$ & $506(49.6)$ \\
\hline
\end{tabular}

HD hemodialysis
Table 4 Patient characteristics: breakdown of total patients and number of patients per facility

\begin{tabular}{|c|c|c|c|}
\hline & $\begin{array}{l}\text { Number of } \\
\text { patients (\%) }\end{array}$ & $\begin{array}{l}\text { Number of patients } \\
\text { per facility, } \\
\text { median (IQR) }\end{array}$ & $\begin{array}{l}\text { Rate of patients } \\
\text { per facility } \\
(\%, \text { mean } \pm \text { SD) }\end{array}$ \\
\hline Total patients & 88,492 & $70(42-110)$ & \\
\hline Inpatients & 8501 (9.6) & $1(0-9)$ & \\
\hline Outpatients & $\begin{array}{l}79,991 \\
(90.4)\end{array}$ & $64(34-104)$ & \\
\hline $\begin{array}{l}\text { Patients aged } \geq 65 \text { years } \\
(n=86,361)\end{array}$ & $\begin{array}{l}54,770 \\
(63.4)\end{array}$ & $44(26-69)$ & $(64.3 \pm 14.4)$ \\
\hline $\begin{array}{l}\text { Patients with albumin } \\
\leq 3.5 \mathrm{~g} / \mathrm{dL}(n=86,136)\end{array}$ & $\begin{array}{l}32,331 \\
(37.6)\end{array}$ & $24(11-41)$ & $(37.6 \pm 20.4)$ \\
\hline
\end{tabular}

$I Q R$ interquartile range, $S D$ standard deviation

pharmacists was not associated with the use of IDPN, similar to the finding for clinical dietitians for ONS ( $p=$ $0.73)$. ET was also less likely to be offered in hospitals $(p<0.01)$ and more likely in clinics with beds $(p=0.03)$. The presence of physical therapists was positively associated with the implementation of ET $(p<0.01)$.

The facilities with higher proportion of the patients aged $\geq 65$ years were more likely to use ONS and IDPN. The facilities with higher proportion of the patients with serum albumin $\leq 3.5 \mathrm{~g} / \mathrm{dL}$ were more likely to use IDPN, but ONS showed no significant difference (Table 6). In the results of the sensitivity analysis, we analyzed the same factors weighted by the reciprocals of the response probabilities and obtained similar results as the original analyses. Moreover, the proportion of the patients with lower albumin levels was positively associated with the implementation of ONS (Table 7). Further sensitivity analysis was conducted using per-100-patient staffing level and indicated similar results, except that the number of doctors was negatively associated with the likelihood of implementation of IDPN and that the number of clinical engineers was no longer significant (Additional file 3: Table S3).

\section{Discussion}

This is the first nationwide survey concerning the types of nutritional therapy and ET for patients on hemodialysis in

Table 5 Facilities and patients providing nutritional therapy and exercise training

\begin{tabular}{llllll}
\hline & $\begin{array}{l}\text { Number of } \\
\text { patients (\%) }\end{array}$ & $\begin{array}{l}\text { Number } \\
\text { of } \\
\text { facilities }\end{array}$ & $\begin{array}{l}\text { Unadjusted } \\
\text { proportion } \\
(\%)\end{array}$ & $\begin{array}{l}\text { Adjusted } \\
\text { proportion } \\
(\%)\end{array}$ & $\begin{array}{l}p \\
\text { value }^{a}\end{array}$ \\
\hline Meals & & 601 & $(61.1)$ & $(63.9)$ & 0.21 \\
ONS & $1873(2.1)$ & 382 & $(38.9)$ & $(39.8)$ & 0.68 \\
IDPN & $2425(2.7)$ & 471 & $(45.3)$ & $(45.8)$ & 0.37 \\
Exercise & $2682(3.0)$ & 190 & $(19.2)$ & $(20.2)$ & 0.57 \\
\hline
\end{tabular}

ONS oral nutritional supplements, IDPN intradialytic parenteral nutrition Proportion of provision was adjusted for facility type and region

annadjusted vs adjusted 


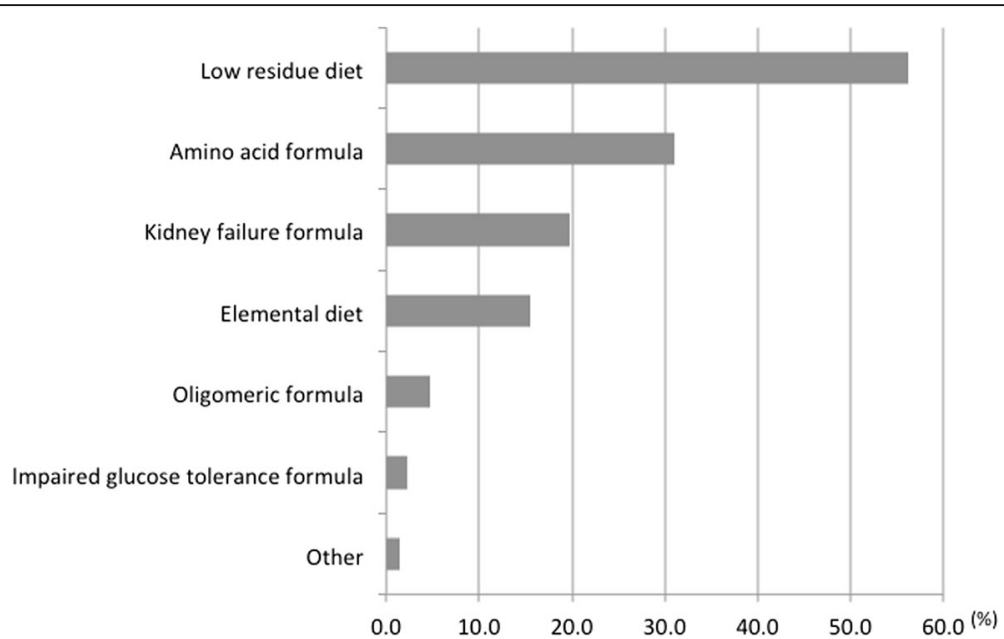

Fig. 1 Types of oral nutritional support. The low residue diet was most commonly used followed by amino acid formula and kidney failure formula. Oral nutritional supplements (ONS) were offered by 399 facilities; however, this answer included multiple answers so the proportion of each component was assessed among 523 answers

Japan. In this study, we adopted age and serum albumin as the patients' characteristics. The proportion of patients aged $\geq 65$ years, which was $63.4 \%$ in this study, was almost identical to that of $61.8 \%$ found by JSDT for the entire Japanese dialysis population [1]. The prevalence of serum albumin $<3.5 \mathrm{~g} / \mathrm{dL}$ was slightly greater at $37.5 \%$ in the present study than the $33.8 \%$ reported in a JSDT survey [22], a difference that may be due to the inclusion or exclusion of patients with serum albumin equal to $3.5 \mathrm{~g} / \mathrm{dL}$.

Approximately $40 \%$ of all facilities were administering ONS, predominantly the low residue diet that can be

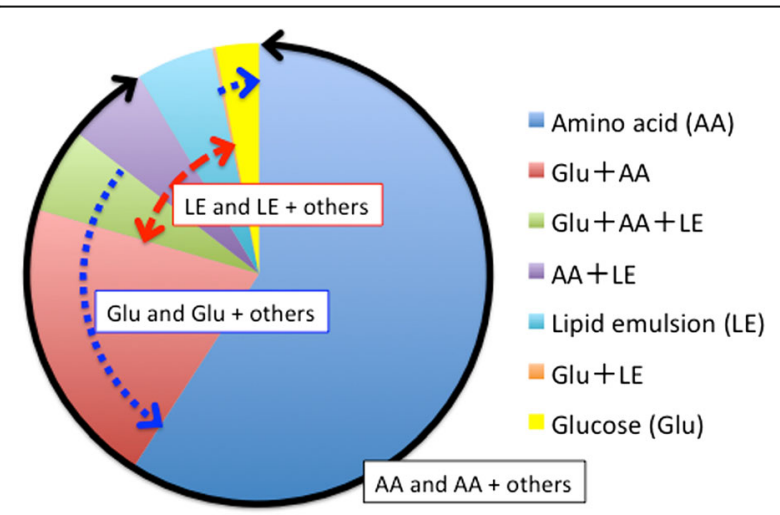

Fig. 2 Types of intradialytic parenteral nutrition. Proportion of each component and the mixtures used among the 2425 patients receiving intradialytic parenteral nutrition (IDPN) are shown. The amino acids formula alone was the most commonly used (59.0\%). Including the combination of amino acids with glucose or lipid emulsion, $91.3 \%$ of patients received IDPN containing amino acids (black arc with arrows at both ends). On the other hand, $29.6 \%$ of the patients received IDPN containing glucose (blue scattered arc with arrows), and only $17.5 \%$ received IDPN containing lipids (red arc with arrows). Abbreviations: $A A$, amino acids; Glu, glucose; LE, lipid emulsion reimbursed by health insurance in Japan and has a wellbalanced nutrient composition. About $50 \%$ of all facilities were offering IDPN. These results were independent of response probability. Although the typical composition of IDPN reported in the literature is a mixture of glucose, amino acids, and lipid emulsion [23], most facilities in the present study used only the amino acid formula for IDPN. This is possibly because the staff focused on the amino acids removed by the dialysis procedure [24]. Other reasons could be the higher costs of lipid emulsion compared with amino acid formula, as well as the time and labor required by medical staff to mix the components for IDPN preparations.

ONS administration may be associated with better survival [12]. Although IDPN did not have an additive effect to ONS in malnourished dialyzed patients [25], IDPN works to facilitate protein anabolism in patients receiving long-term hemodialysis in the acute phase [26]. This is evidenced by significant concomitant increases in lean body mass and albumin synthesis in the liver [27]. Therefore, both ONS and IDPN can potentially ameliorate malnutrition. In the present study, the proportion of patients treated by nutritional therapy was as small as $2 \%$, while the proportion of patients with serum albumin $\leq 3.5 \mathrm{~g} / \mathrm{dL}$ was as high as $37.5 \%$. Therefore, it is possible that patients who should have been treated by nutritional therapy did not receive it. However, hypoalbuminemia is not the sole indication for nutritional therapy, and this criterion could overestimate the actual proportion of patients needing nutritional therapy. Further clarification of the indications for nutritional therapy is required in actual clinical practice. A positive point to note, however, is that logistic analysis showed nutritional therapy is being administered to patients with low nutrition in some facilities in Japan. 


\section{a Type of Exercise}

- RT only $₫$ AT only $₫$ RT+AT $₫$ Other

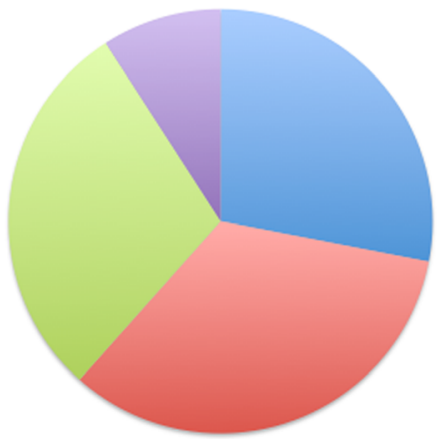

\section{b Frequency of Exercise}

\author{
- Thrice weekly $=$ Twice weekly \\ Once weekly Undetermined
}

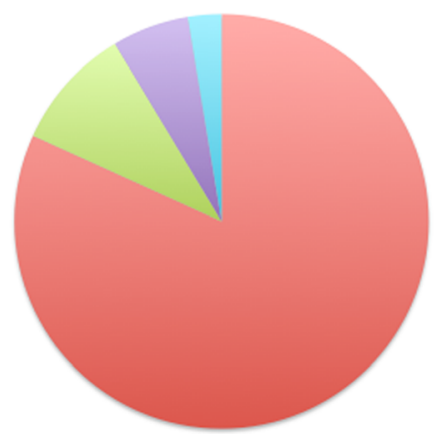

Fig. 3 Types and frequency of exercise training. Approximately 30\% of patients underwent resistance training (RT) alone, aerobic training (AT) alone, or RT and AT (A). Further, 82\% of patients exercised three times per week (B)

ET was enforced in about $20 \%$ of the facilities, and only $3 \%$ of all the patients were receiving ET. Patients on dialysis have extremely limited exercise capacity and poor physical functioning [28]. It has been reported that sedentary behavior in patients on hemodialysis is associated with an increased risk of death within 1 year even after adjusting for all covariates [29]. However, ET might increase aerobic capacity, muscle mass or strength, physical quality of life, and $\mathrm{Kt} / \mathrm{V}[16,30]$. Additionally, ET during dialysis therapy is associated with few adverse events $[16,31,32]$. However, a study from the Dialysis Outcomes and Practice Patterns Study (DOPPS) showed that the percentage of units offering exercise programs was 14\% in Japan from 2009 to 2011, while 27 and $37 \%$ of the facilities offered ET in Europe or Australia/New Zealand and in North America, respectively [33]. This difference between DOPPS and our study might indicate an increase in the facilities offering ET over the last few years, as the benefits of ET have become widely accepted.
ET performed on non-dialysis days is reportedly the most effective way of training, although difficulties in maintaining adherence have been demonstrated [34]. In the present study, a limited number of facilities (up to $20 \%$ ) provided ET on hemodialysis days and only $9 \%$ provided ET on non-hemodialysis days. DOPPS showed that the proportion of facilities providing ET on dialysis and non-dialysis days was about $10 \%$ in japan from 2005 to 2006 [35]. After a decade, we found the facilities offering the exercise program on dialysis is increasing as discussed above, but the facilities offering ET on non-dialysis days have not increased. Recently it reported that two daily 10-min walking sessions during the off-dialysis days (every second day for patients on peritoneal dialysis) at a prescribed walking speed may improve physical performance and quality of life [36]. Our findings indicate that the awareness of ET needs to be further improved.

Each intervention type accounting for almost onethird of ET. Recently many studies have reported the evidences about exercise for dialysis patients. But the

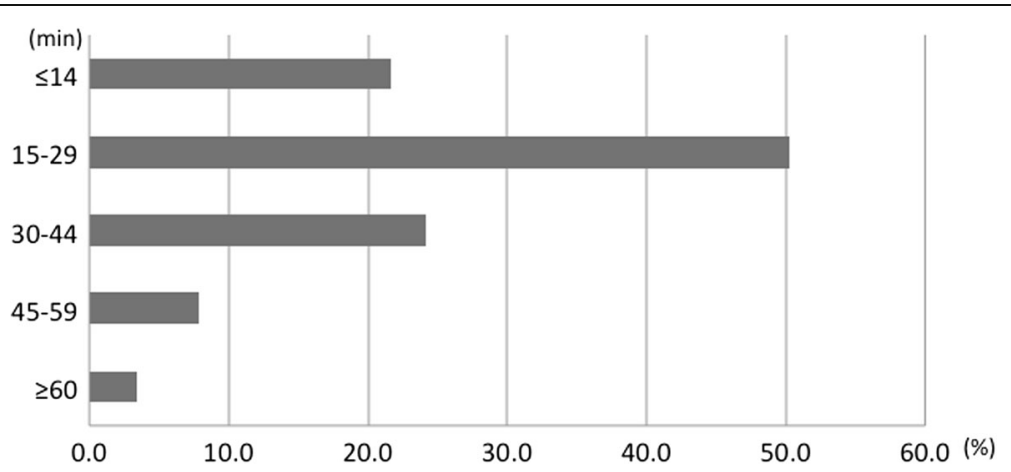

Fig. 4 Exercise duration. Half of the patients underwent exercise for 15-29 min during a single session 
Table 6 Logistic regression analysis

\begin{tabular}{|c|c|c|c|c|c|c|c|c|c|c|}
\hline \multicolumn{2}{|l|}{ Variable } & \multicolumn{3}{|l|}{ ONS } & \multicolumn{3}{|l|}{ IDPN } & \multicolumn{3}{|c|}{ Exercise } \\
\hline & & OR & $(95 \% \mathrm{Cl})$ & $p$ value & OR & $(95 \% \mathrm{Cl})$ & $p$ value & OR & $(95 \% \mathrm{Cl})$ & $p$ value \\
\hline \multicolumn{2}{|l|}{ Clinic } & 1 & reference & & 1 & reference & & 1 & reference & \\
\hline \multicolumn{2}{|l|}{ Clinic with beds } & 0.66 & $0.38-1.11$ & 0.12 & 1.15 & $0.68-1.96$ & 0.60 & 0.50 & $0.28-0.95$ & 0.03 \\
\hline \multicolumn{2}{|c|}{ Hospital (< 200 beds) } & 0.49 & $0.22-1.05$ & 0.07 & 0.50 & $0.23-1.10$ & 0.08 & 0.20 & $0.08-0.49$ & $<0.01$ \\
\hline \multicolumn{2}{|c|}{ Hospital ( $\geq 200$ beds) } & 0.21 & $0.09-0.45$ & $<0.001$ & 0.37 & $0.17-0.82$ & 0.01 & 0.08 & $0.03-0.20$ & $<0.001$ \\
\hline \multirow[t]{4}{*}{ Doctor } & Q1 & 1 & reference & & 1 & reference & & 1 & reference & \\
\hline & Q2 & 0.95 & $0.59-1.53$ & 0.83 & 0.76 & $0.48-1.21$ & 0.25 & 0.85 & $0.46-1.63$ & 0.62 \\
\hline & Q3 & 0.62 & $0.37-1.05$ & 0.08 & 0.64 & $0.38-1.07$ & 0.09 & 0.97 & $0.50-1.94$ & 0.94 \\
\hline & Q4 & 0.85 & $0.50-1.45$ & 0.55 & 0.86 & $0.51-1.45$ & 0.56 & 1.39 & $0.71-2.79$ & 0.34 \\
\hline \multirow[t]{4}{*}{ Nurse } & Q1 & 1 & reference & & 1 & reference & & 1 & reference & \\
\hline & Q2 & 1.21 & $0.81-1.84$ & 0.36 & 0.83 & $0.55-1.24$ & 0.36 & 1.00 & $0.56-1.79$ & 1.00 \\
\hline & Q3 & 1.71 & $1.14-2.60$ & 0.01 & 1.70 & $1.14-2.56$ & $<0.01$ & 1.66 & $0.98-2.83$ & 0.06 \\
\hline & Q4 & 1.64 & $1.03-2.60$ & 0.04 & 1.71 & $1.08-2.70$ & 0.02 & 1.58 & $0.90-2.81$ & 0.11 \\
\hline \multirow[t]{4}{*}{ Clinical engineer } & Q1 & 1 & reference & & 1 & reference & & 1 & reference & \\
\hline & Q2 & 1.17 & $0.67-2.06$ & 0.58 & 1.51 & $0.88-2.63$ & 0.13 & 1.59 & $0.73-3.80$ & 0.25 \\
\hline & Q3 & 1.92 & $1.09-3.44$ & 0.03 & 2.65 & $1.51-4.71$ & $<0.001$ & 1.95 & $0.88-4.72$ & 0.10 \\
\hline & Q4 & 2.76 & $1.56-5.00$ & $<0.001$ & 3.32 & $1.88-5.95$ & $<0.001$ & 5.93 & $2.76-14.03$ & $<0.001$ \\
\hline \multicolumn{2}{|c|}{ Presence of pharmacist (vs absence) } & 0.99 & $0.54-1.81$ & 0.98 & 0.90 & $0.49-1.66$ & 0.73 & 1.03 & $0.50-2.07$ & 0.93 \\
\hline \multicolumn{2}{|c|}{ Presence of clinical dietitian (vs absence) } & 1.13 & $0.73-1.73$ & 0.59 & 1.01 & $0.65-1.55$ & 0.97 & 1.94 & $1.15-3.29$ & 0.01 \\
\hline \multicolumn{2}{|c|}{ Presence of physical therapist (vs absence) } & 1.84 & $1.05-3.28$ & 0.03 & 1.95 & $1.09-3.55$ & 0.02 & 3.48 & $1.85-6.66$ & $<0.001$ \\
\hline \multirow[t]{6}{*}{ Regions } & Hokkaido/Tohoku & 0.79 & $0.44-1.27$ & 0.29 & 1.58 & $0.95-2.64$ & 0.08 & 2.85 & $1.48-5.46$ & $<0.01$ \\
\hline & Kanto & 1 & reference & & 1 & reference & & 1 & reference & \\
\hline & Chubu/Tokai & 1.01 & $0.63-1.60$ & 0.97 & 1.62 & $1.03-2.58$ & 0.04 & 2.05 & $1.12-3.73$ & 0.02 \\
\hline & Kansai & 1.00 & $0.64-1.56$ & 1.00 & 1.76 & $1.13-2.76$ & 0.01 & 1.98 & $1.10-3.52$ & 0.02 \\
\hline & Chugoku/Shikoku & 0.90 & $0.51-1.57$ & 0.71 & 1.51 & $0.87-2.63$ & 0.15 & 2.03 & $0.97-4.16$ & 0.06 \\
\hline & Kyushu/Okinawa & 0.76 & $0.44-1.30$ & 0.31 & 0.72 & $0.42-1.23$ & 0.23 & 2.69 & $1.37-5.29$ & $<0.01$ \\
\hline \multicolumn{2}{|c|}{ Patients aged $\geq 65$ years (per 10\%) } & 1.14 & $1.01-1.28$ & 0.03 & 1.16 & $1.03-1.30$ & 0.01 & 1.07 & $0.93-1.25$ & 0.35 \\
\hline \multicolumn{2}{|c|}{ Patients with albumin $\leq 3.5 \mathrm{~g} / \mathrm{dL}$ (per 10\%) } & 1.03 & $0.95-1.12$ & 0.44 & 1.09 & $1.01-1.17$ & 0.03 & 0.95 & $0.86-1.05$ & 0.35 \\
\hline
\end{tabular}

Abbreviations: $O R$ odds ratio, $\mathrm{Cl}$, confidence interval

best way to offer ET in dialysis patients remains unclear. The current study demonstrated that the actual types of ET were diverse across the facility offering ET. Many investigations have employed ET as an intervention for at least $30 \mathrm{~min}$, three times a week [16]. The duration of ET in Japanese facilities was found to be shorter in this study, possibly because the Japanese dialysis population investigated here was older than that in the reported clinical trials (aged 40-50 years) [16].

DOPPS reported an important finding: patients who exercise regularly showed better survival than those who do not (HR 0.73, 95\% CI 0.69-0.78); moreover, patients who received treatment at a facility with a higher frequency of exercise also had better survival (HR per $10 \%$ increase in regularly exercising patients $0.92,95 \%$ CI 0.89-0.94) [35]. These results demonstrate that the practice patterns implemented in a facility could affect the clinical outcomes of patients treated at that facility. So it is important for every dialysis facility to be aware of the usefulness and safety of ET in order to prevent PEW progression to further unfavorable outcomes. In fact, over half of the total facilities included in this survey intended to offer ET.

The present investigation into the background factors relating to the implementation of these therapies indicated that clinics tend to offer such therapies rather than hospitals. In general, clinics without beds manage larger numbers of chronic patients over longer terms, enabling them to provide these therapies more frequently than the other facility types. In contrast, we can consider that the patients in hospitals have different characteristics from those in clinics; they require the treatment for acute conditions because the hospitalized 
Table 7 Logistic regression analysis with inverse probability of response rate weighting for facility type and region

\begin{tabular}{|c|c|c|c|c|c|c|c|c|c|c|}
\hline \multicolumn{2}{|l|}{ Variable } & \multicolumn{3}{|l|}{ ONS } & \multicolumn{3}{|l|}{ IDPN } & \multicolumn{3}{|c|}{ Exercise } \\
\hline & & OR & $(95 \% \mathrm{Cl})$ & $p$ value & OR & $(95 \% \mathrm{Cl})$ & $p$ value & OR & $(95 \% \mathrm{Cl})$ & $p$ value \\
\hline \multicolumn{2}{|l|}{ Clinic } & 1 & reference & & 1 & reference & & 1 & reference & \\
\hline \multicolumn{2}{|l|}{ Clinic with beds } & 0.68 & $0.52-0.88$ & $<0.01$ & 1.18 & $0.96-1.54$ & 0.22 & 0.56 & $0.41-0.78$ & $<0.001$ \\
\hline \multicolumn{2}{|c|}{ Hospital (< 200 beds) } & 0.51 & $0.36-0.73$ & $<0.001$ & 0.59 & $0.41-0.85$ & $<0.01$ & 0.24 & $0.16-0.37$ & $<0.001$ \\
\hline \multicolumn{2}{|c|}{ Hospital ( $\geq 200$ beds) } & 0.22 & $0.15-0.33$ & $<0.001$ & 0.43 & $029-0.64$ & $<0.001$ & 0.10 & $0.06-0.16$ & $<0.001$ \\
\hline \multirow[t]{4}{*}{ Doctor } & Q1 & 1 & reference & & 1 & reference & & 1 & reference & \\
\hline & Q2 & 0.94 & $0.74-1.18$ & 0.56 & 0.89 & $0.71-1.12$ & 0.33 & 0.88 & $0.65-1.20$ & 0.41 \\
\hline & Q3 & 0.59 & $0.46-0.76$ & $<0.001$ & 0.66 & $0.52-0.85$ & $<0.01$ & 0.88 & $0.64-1.23$ & 0.46 \\
\hline & Q4 & 0.85 & $0.66-1.09$ & 0.20 & 0.84 & $0.65-1.08$ & 0.18 & 1.64 & $1.19-2.30$ & $<0.01$ \\
\hline \multirow[t]{4}{*}{ Nurse } & Q1 & 1 & reference & & 1 & reference & & 1 & reference & \\
\hline & Q2 & 1.07 & $0.87-1.30$ & 0.52 & 0.89 & $0.73-1.08$ & 0.23 & 1.14 & $0.87-1.51$ & 0.34 \\
\hline & Q3 & 1.65 & $1.35-2.01$ & $<0.001$ & 1.76 & $1.45-2.14$ & $<0.001$ & 1.73 & $1.34-2.24$ & $<0.001$ \\
\hline & Q4 & 1.62 & $1.30-2.01$ & $<0.001$ & 1.69 & $1.35-2.10$ & $<0.001$ & 1.70 & $1.30-2.24$ & $<0.01$ \\
\hline \multirow[t]{4}{*}{ Clinical engineer } & Q1 & 1 & reference & & 1 & reference & & 1 & reference & \\
\hline & Q2 & 1.10 & $0.85-1.43$ & 0.47 & 1.46 & $1.13-1.89$ & $<0.01$ & 1.77 & $1.21-2.65$ & $<0.01$ \\
\hline & Q3 & 1.84 & $1.41-2.42$ & $<0.001$ & 2.74 & $2.10-3.60$ & $<0.001$ & 1.93 & $1.30-2.93$ & $<0.01$ \\
\hline & Q4 & 2.66 & $1.41-3.51$ & $<0.001$ & 3.36 & $2.56-4.44$ & $<0.001$ & 6.36 & $4.34-9.52$ & $<0.001$ \\
\hline \multicolumn{2}{|c|}{ Presence of pharmacist (vs absence) } & 1.05 & $0.78-1.41$ & 0.76 & 0.81 & $0.60-1.10$ & 0.17 & 1.04 & $0.74-1.47$ & 0.80 \\
\hline \multicolumn{2}{|c|}{ Presence of clinical dietitian (vs absence) } & 1.13 & $0.91-1.40$ & 0.26 & 1.02 & $0.82-1.27$ & 0.83 & 2.05 & $1.58-2.66$ & $<0.001$ \\
\hline \multicolumn{2}{|c|}{ Presence of physical therapist (vs absence) } & 1.76 & $1.36-2.29$ & $<0.001$ & 1.97 & $1.51-2.59$ & $<0.001$ & 2.41 & $1.80-3.25$ & $<0.001$ \\
\hline \multirow[t]{6}{*}{ Regions } & Hokkaido/Tohoku & 0.69 & $0.54-1.27$ & $<0.01$ & 1.60 & $1.24-2.07$ & $<0.001$ & 2.86 & $2.06-3.96$ & $<0.001$ \\
\hline & Kanto & 1 & reference & & 1 & reference & & 1 & reference & \\
\hline & Chubu/Tokai & 0.99 & $0.72-1.12$ & 0.33 & 1.52 & $1.23-1.90$ & $<0.001$ & 2.33 & $1.76-3.07$ & $<0.001$ \\
\hline & Kansai & 1.00 & $0.80-1.23$ & 0.92 & 1.53 & $1.24-1.91$ & $<0.001$ & 1.77 & $1.33-2.34$ & $<0.001$ \\
\hline & Chugoku/Shikoku & 0.71 & $0.55-0.92$ & $<0.01$ & 1.35 & $1.05-1.75$ & 0.02 & 2.40 & $1.72-3.33$ & $<0.001$ \\
\hline & Kyushu/Okinawa & 0.63 & $0.49-0.81$ & $<0.001$ & 0.63 & $0.49-0.81$ & $<0.001$ & 3.00 & $2.20-4.09$ & $<0.001$ \\
\hline \multicolumn{2}{|c|}{ Patients aged $\geq 65$ years (per 10\%) } & 1.13 & $1.07-1.20$ & $<0.001$ & 1.22 & $1.16-1.30$ & $<0.001$ & 1.04 & $0.96-1.11$ & 0.34 \\
\hline \multicolumn{2}{|c|}{ Patients with albumin $\leq 3.5 \mathrm{~g} / \mathrm{dL}$ (per 10\%) } & 1.04 & $1.00-1.08$ & 0.03 & 1.09 & $1.06-1.14$ & $<0.001$ & 0.98 & $0.93-1.03$ & 0.36 \\
\hline
\end{tabular}

Abbreviations: $O R$ odds ratio, $\mathrm{Cl}$ confidence interval

patients in other nephrology department tend to have many comorbidities.

The results obtained from the analyses where staff number was standardized by patient number confirmed that IDPN is being predominantly offered in clinics without beds.

Interestingly, our results indicate that the number of staff-key elements of each facility-was positively correlated with the implementation of nutritional therapy or ET. In particular, the results obtained from the analyses standardized by facility type and region revealed stronger associations between these factors.

Curiously, the proportions of the older patients or the patients with lower albumin levels were positively associated with the implementation of ONS or IDPN. On the other hand, ET did not have such associations with the proportions of the patients with such background. This fact shows the medical director of the facility might have different criteria to implement ET from those for ONS and IDPN.

Surprisingly, the provision of ONS or IDPN was independent of the presence of dietitians or pharmacists in the facility. This might indicate these therapies might be readily available irrespective of the professionals available, although the involvement of dietitians or pharmacists might improve the quality or effectiveness of these therapies.

There are several limitations to this study. The first is that this observational study did not examine the data of individual patients. Therefore, we could not investigate the detailed relationship between patient characteristics and the interventions or clinical outcomes. However, the aim of the study was to investigate the overall status of these therapies in Japan, which has not been investigated previously. Second, the response rate for the 
questionnaire was not high $26 \%$ of all facilities. Although detailed patient characteristics were not investigated and we cannot eliminate the effects of differences in patients characteristics between responded and non-responded facilities, the proportions of older patients or the patients with albumin of $3.5 \mathrm{~g} / \mathrm{dl}$ or less were not virtually different from the entire dialysis population in Japan. On the other hand, the response rate did differ across the facility types. However, adjustment by affiliations of facility type or region yielded no significant differences in the proportion of facilities offering these interventions.

\section{Conclusions}

Many hemodialysis facilities provided nutritional intervention and for ET are also increasing, while a limited number of patients provided ET. And the number of staff was positively correlated with the implementation of nutritional therapy or ET. We consider it important to assess the indications for nutritional therapies and ET for each patient appropriately and to provide patients with appropriate and detailed knowledge about such therapies for their proper and wider use. Moreover, the standardization of nutritional therapy and ET is needed in the future.

\section{Additional files}

Additional file 1: Item S1. Questionnaire. (PDF 194 kb)

Additional file 2: Table S2. Proportion of facilities providing

interventions based on lower and higher response probabilities. (PDF 88 kb)

Additional file 3: Table S3. Logistic regression analysis with conducted using per-100-patient staffing level. (PDF $111 \mathrm{~kb}$ )

\begin{abstract}
Abbreviations
95\% Cl: 95\% confidence interval; AA: Amino acids; AT: Aerobic training; DOPPS: The Dialysis Outcomes and Practice Patterns Study; ESPEN: The European Society for Clinical Nutrition and Metabolism; Glu: Glucose; IDPN: Intradialytic parenteral nutrition; IQR: Interquartile ranges; JSDT: The Japanese Society for Dialysis Therapy; LE: Lipid emulsion; ONS: Oral nutritional supplements; OR: Odds ratio; PEW: Protein energy wasting; RT: Resistance training
\end{abstract}

\section{Acknowledgements}

We are grateful to all the staff who took time responding to the questionnaire. The abstract of this article was presented at the 17th International Congress on Nutrition and Metabolism in Renal Disease, Okinawa, in April 2016; the 61st Annual Meeting of the Japanese Society for Dialysis Therapy, Osaka, in June 2016; and the 4th the Japanese Society on Renal Nutrition and Metabolism, Kobe, in June 2016.

\section{Funding}

None to declare.

\section{Availability of data and materials}

At the time of the data collection, we did not ask the facilities that the data will be shared. Therefore, we consider the database cannot be made accessible.

\section{Authors' contributions}

SS and NH designed the study, collected and analyzed the data, and wrote the draft version of the manuscript. SI and RM contributed to the questionnaire design. SI contributed to the data analysis. HK, RM, and MN reviewed and finalized the manuscript for intellectual content. All authors read and approved the final manuscript.

Ethics approval and consent to participate

The study was approved by the Ethics Committee of the University of Tokyo School of Medicine on 7 September 2015 (approval number 10943).

Consent for publication

Not applicable.

\section{Competing interests}

Satoko Sakurai: none. Norio Hanafusa: $\mathrm{NH}$ received research funding from Meiji Co., Ltd., a manufacturer of oral nutritional supplements and was also a former member of a division that is funded by Terumo Corporation. However, this study has no association with that funding and the relationship did not affect the interpretation of this study's results. Hideki Kato: none. Shinji lizaka: none. Ryoko Murayama: RM is a member of a division that is funded by Terumo Corporation. However, this study has no association with that funding and the relationship did not affect the interpretation of this study's results. Masaomi Nangaku: MN served as consultancy or advisory boards of Akebia, Bayer, Kyowa Hakko Kirin, Daiichi Sankyo, Astellas, Taisho, Mitsubishi Tanabe, JT, speaker bureaus of Kyowa Hakko Kirin, Daiichi Sankyo, MSD, Astellas, AstraZeneca, Alexion, Mitsubishi Tanabe, JT, and Chugai. However, this study has no association with that funding and the relationship did not affect the interpretation of this study's results. This research did not receive any specific grant from funding agencies in the public, commercial, or not-for-profit sectors.

\section{Publisher's Note}

Springer Nature remains neutral with regard to jurisdictional claims in published maps and institutional affiliations.

\section{Author details}

${ }^{1}$ Division of Nephrology and Endocrinology, The University of Tokyo Graduate School of Medicine, Tokyo, Japan. ${ }^{2}$ Department of Blood Purification, Kidney Center Tokyo Women's Medical University, 8-1 Kawada-cho, Shinjuku-ku, Tokyo 162-8666, Japan. ${ }^{3}$ School of Nutrition, College of Nursing and Nutrition, Shukutoku University, Chiba, Japan. ${ }^{4}$ Department of Advanced Nursing Technology, The University of Tokyo Graduate School of Medicine, Tokyo, Japan.

Received: 6 June 2017 Accepted: 27 November 2017 Published online: 19 December 2017

\section{References}

1. Masakane I, Nakai S, Ogata S, et al. An overview of regular dialysis treatment in Japan (as of 31 December 2013). Ther Apher Dial. 2015;19:540-74.

2. Cruz-Jentoft AJ, Baeyens JP, Bauer JM, et al. Sarcopenia: European consensus on definition and diagnosis: report of the European working group on sarcopenia in older people. Age Ageing. 2010;39:412-23.

3. Fried LP, Tangen CM, Walston J, et al. Frailty in older adults: evidence for a phenotype. J Gerontol A Biol Sci Med Sci. 2001;56:M146-56.

4. Isoyama N, Qureshi AR, Avesani CM, et al. Comparative associations of muscle mass and muscle strength with mortality in dialysis patients. Clin J Am Soc Nephrol. 2014;9:1720-8.

5. Johansen KL, Chertow GM, Jin C, Kutner NG. Significance of frailty among dialysis patients. J Am Soc Nephrol. 2007;18:2960-7.

6. Kalantar-Zadeh K, Kilpatrick RD, Kuwae N, et al. Revisiting mortality predictability of serum albumin in the dialysis population: time dependency, longitudinal changes and population-attributable fraction. Nephrol Dial Transplant. 2005:20:1880-8.

7. Kim JC, Kalantar-Zadeh K, Kopple JD. Frailty and protein-energy wasting in elderly patients with end stage kidney disease. J Am Soc Nephrol. 2013;24:337-51.

8. Fouque D, Kalantar-Zadeh K, Kopple J, et al. A proposed nomenclature and diagnostic criteria for protein-energy wasting in acute and chronic kidney disease. Kidney Int. 2008;73:391-8.

9. Rockwood K, Stadnyk K, MacKnight C, McDowell I, Hebert R, Hogan DB. A brief clinical instrument to classify frailty in elderly people. Lancet. 1999;353:205-6. 
10. Sohrabi Z, Eftekhari MH, Eskandari MH, Rezaianzadeh A, Sagheb MM. Intradialytic oral protein supplementation and nutritional and inflammation outcomes in hemodialysis: a randomized controlled trial. Am J Kidney Dis. 2016;68:122-30.

11. Weiner DE, Tighiouart H, Ladik V, Meyer KB, Zager PG, Johnson DS. Oral intradialytic nutritional supplement use and mortality in hemodialysis patients. Am J Kidney Dis. 2014;63:276-85.

12. Lacson E Jr, Wang W, Zebrowski B, Wingard R, Hakim RM. Outcomes associated with intradialytic oral nutritional supplements in patients undergoing maintenance hemodialysis: a quality improvement report. Am J Kidney Dis. 2012;60:591-600.

13. Caglar K, Fedje L, Dimmitt R, Hakim RM, Shyr Y, Ikizler TA. Therapeutic effects of oral nutritional supplementation during hemodialysis. Kidney Int. 2002;62:1054-9.

14. Kistler B, Benner D, Burgess M, Stasios M, Kalantar-Zadeh K, Wilund KR. To eat or not to eat-international experiences with eating during hemodialysis treatment. J Ren Nutr. 2014;24:349-52.

15. Benner D, Burgess M, Stasios M, et al. In-center nutrition practices of clinics within a large hemodialysis provider in the United States. Clin J Am Soc Nephrol. 2016;11:770-5.

16. Sheng K, Zhang P, Chen L, Cheng J, Wu C, Chen J. Intradialytic exercise in hemodialysis patients: a systematic review and meta-analysis. Am J Nephrol. 2014:40:478-90.

17. Heiwe $\mathrm{S}$, Jacobson SH. Exercise training in adults with CKD: a systematic review and meta-analysis. Am J Kidney Dis. 2014;64:383-93.

18. Segura-Orti E. Exercise in haemodyalisis patients: a literature systematic review. Nefrologia. 2010;30:236-46.

19. Military of Health Labour and Welfare. Survey of Medical facilities 2013. [http:// www.mhlw.go.jp/toukei/saikin/hw/iryosd/13/dl/1-1.pdf] Accessed 1 Sep 2017

20. Ouchi $\mathrm{Y}$, Rakugi $\mathrm{H}$, Arai $\mathrm{H}$, et al. Redefining the elderly as aged 75 years and older: proposal from the Joint Committee of Japan Gerontological Society and the Japan Geriatrics Society. Geriatr Gerontol Int. 2017;17:1045-7.

21. Cano NJ, Aparicio M, Brunori G, et al. ESPEN guidelines on parenteral nutrition: adult renal failure. Clin Nutr. 2009;28:401-14.

22. Japanese Society for Dialysis Therapy. An overview of regular dialysis treatment in Japan as of Dec.31 2015. [http://member.jsdt.or.jp/member/ contents/cdrom/2015/pdf/chohyo/IMP04176.pdf] Accessed 1 Sep 2017.

23. Fouque D. Causes and interventions for malnutrition in patients undergoing maintenance dialysis. Blood Purif. 1997;15:112-20.

24. Ikizler TA, Flakoll PJ, Parker RA, Hakim RM. Amino acid and albumin losses during hemodialysis. Kidney Int. 1994;46:830-7.

25. Cano NJ, Fouque D, Roth $\mathrm{H}$, et al. Intradialytic parenteral nutrition does not improve survival in malnourished hemodialysis patients: a 2-year multicenter, prospective, randomized study. J Am Soc Nephrol. 2007;18:2583-91.

26. Hiroshige K, Iwamoto M, Kabashima N, Mutoh Y, Yuu K, Ohtani A. Prolonged use of intradialysis parenteral nutrition in elderly malnourished chronic haemodialysis patients. Nephrol Dial Transplant. 1998;13:2081-7.

27. Pupim LB, Flakoll PJ, Ikizler TA. Nutritional supplementation acutely increases albumin fractional synthetic rate in chronic hemodialysis patients. J Am Soc Nephrol. 2004;15:1920-6.

28. Johansen KL. Physical functioning and exercise capacity in patients on dialysis. Adv Ren Replace Ther. 1999;6:141-8.

29. O'Hare AM, Tawney K, Bacchetti P, Johansen KL. Decreased survival among sedentary patients undergoing dialysis: results from the dialysis morbidity and mortality study wave 2. Am J Kidney Dis. 2003:41:447-54.

30. Ikizler TA. Exercise as an anabolic intervention in patients with end-stage renal disease. J Ren Nutr. 2011:21:52-6.

31. Smart N, Steele M. Exercise training in haemodialysis patients: a systematic review and meta-analysis. Nephrol (Carlton). 2011;16:626-32.

32. Cheema BS, Singh MA. Exercise training in patients receiving maintenance hemodialysis: a systematic review of clinical trials. Am J Nephrol. 2005;25:352-64.

33. Lopes AA, Lantz B, Morgenstern H, et al. Associations of self-reported physical activity types and levels with quality of life, depression symptoms, and mortality in hemodialysis patients: the DOPPS. Clin J Am Soc Nephrol. 2014;9:1702-12.

34. Konstantinidou E, Koukouvou G, Kouidi E, Deligiannis A, Tourkantonis A. Exercise training in patients with end-stage renal disease on hemodialysis: comparison of three rehabilitation programs. J Rehabil Med. 2002:34:40-5.

35. Tentori F, Elder SJ, Thumma J, et al. Physical exercise among participants in the dialysis outcomes and practice patterns study (DOPPS): correlates and associated outcomes. Nephrol Dial Transplant. 2010;25:3050-62.

36. Manfredini F, Mallamaci F, D'Arrigo G, et al. Exercise in patients on dialysis: a multicenter, randomized clinical trial. J Am Soc Nephrol. 2017;28:1259-68.

\section{Submit your next manuscript to BioMed Central and we will help you at every step:}

- We accept pre-submission inquiries

- Our selector tool helps you to find the most relevant journal

- We provide round the clock customer support

- Convenient online submission

- Thorough peer review

- Inclusion in PubMed and all major indexing services

- Maximum visibility for your research

Submit your manuscript at www.biomedcentral.com/submit
Biomed Central 